\title{
ПРОБЛЕМЫ ОЦЕНКИ КАЧЕСТВА ОБРАЗОВАНИЯ В ВЫСШЕЙ ШКОЛЕ В УСЛОВИЯХ ПЕРЕХОДА НА ДИСТАНЦИОННОЕ ОБУЧЕНИЕ В РОССИЙСКОЙ ФЕДЕРАЦИИ
}

\author{
(c) 2020 Николаева Елена Анатольевна \\ кандидат социологических наук, доцент, кафедра иностранных языков № 3 \\ Российский экономический университет им. Г. В. Плеханова, Россия, Москва \\ E-mail:yoltash82@mail.ru \\ (C) 2020 Кузнецова Юлия Андреевна \\ кандидат экономических наук, доцент, кафедра иностранных языков № 3 \\ Российский экономический университет им. Г. В. Плеханова, Россия, Москва \\ E-mail: yulia_success@mail.ru \\ (c) 2020 Сидорова Елена Евгеньевна \\ старший преподаватель, кафедра иностранных языков № 3 \\ Российский экономический университет им. Г. В. Плеханова, Россия, Москва \\ E-mail: iksharik@gmail.com

\section{(c) 2020 Соколова Екатерина Иосифовна} \\ кандидат филологических наук, доцент, кафедра иностранных языков № 3 \\ Российский экономический университет им. Г. В.Плеханова, Россия, Москва \\ E-mail:kafmkk@mail.ru
}

В статье дается обзор проблемам оценки качества образования в высшей школе в условиях перехода на дистанционное обучение в Российской Федерации. Объектом исследования выступило образование в высшей школе, а предметом - проблемы его оценки в условиях перехода на дистанционное обучение. Теоретическое и методологическое значение исследования заключены в развитии теории и методологии оценки качества образования. Практическое значение исследования заключается в систематизации проблем оценки качества образования в высшей школе Российской Федерации в условиях перехода на дистанционное обучение.

Ключевые слова: Проблемы, оценка, качество, образование, высшая школа, условия, переход, дистанционное обучение.

Современная социальная и экономическая действительность, возникшая в результате глобальной проблемы в начале 2020 года [6], заставляет социум переосмысливать многие уже ставшие традиционными подходы и процессы внутри одной географической формации. Так, например, значительным изменениям в проекции социального дистанцирования подверглись такие сферы, как образование, трудовая деятельность, транспортировка, шопинг и многое другое.

По данным исследований, проведенных всемирно известной консалтинговой фирмой PricewaterhouseCoopers [7] в середине 2020 года, удаленный формат работы $[2,5]$ в сложившихся кризисных условиях признали оправданным в среднем более 90 процентов от опрошенных респондентов в большинстве развитых стран. Вы- держки из результатов данного исследования на начало 2 квартала 2020 года приведены на рисунке 1.

Как можно увидеть из рисунка наибольшие средние уровни целесообразности введения удаленных (социально дистанцированных) форматов работы признали респонденты таких стран, как США (в среднем по стране порядка 95,85 процентов оправданности), Италия (в среднем по стране порядка 94,11 процентов оправданности) и Китай (в среднем по стране порядка 93,95 процентов оправданности).

Следует отметить, что одними из первых на удаленный формат работы в условия пандемии были переведены такие сферы, как трудовая деятельность и образование, которые наиболее остро, в дальнейшем, нуждались в оценке и анализе качества их осуществления. 


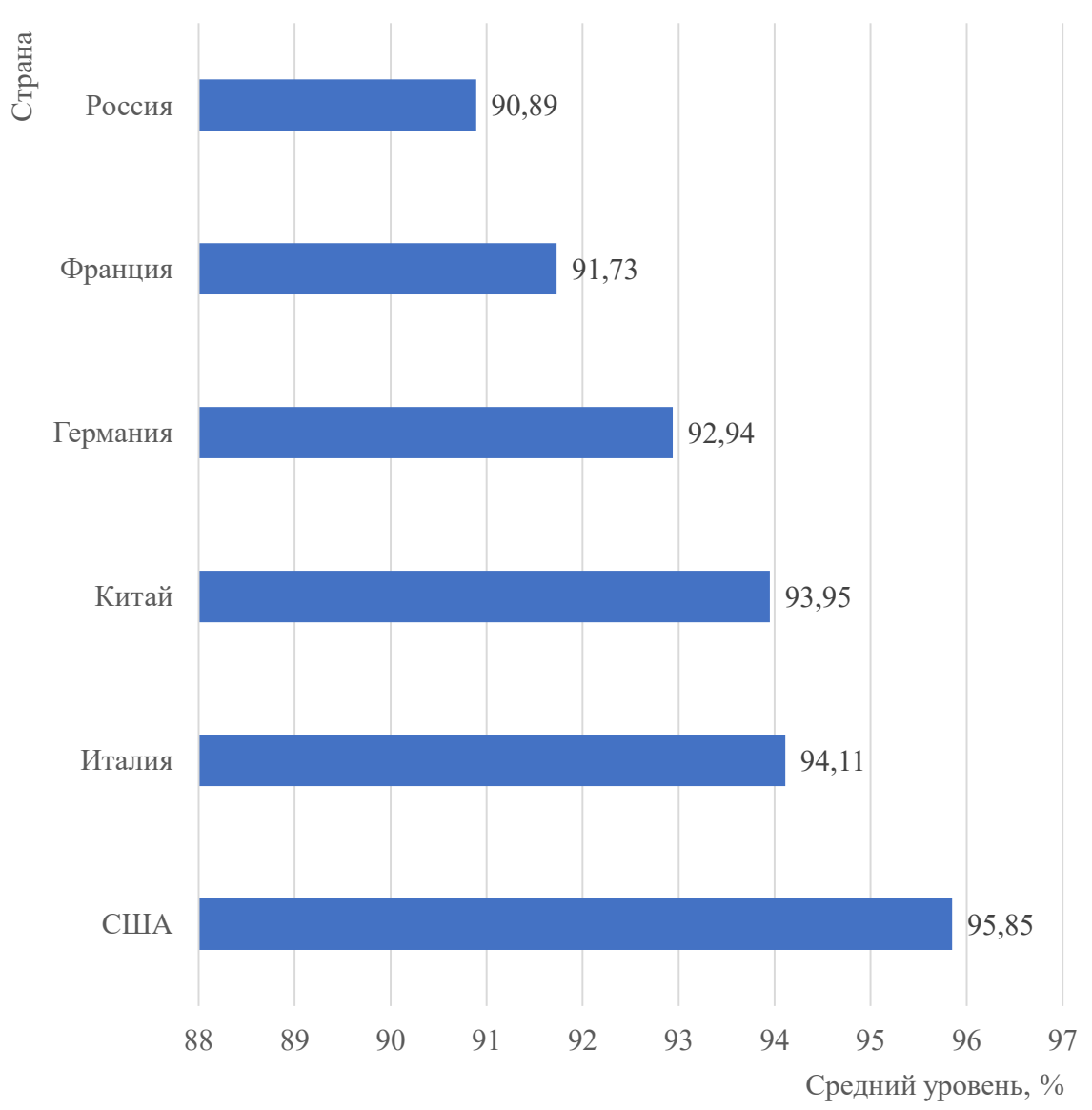

Puc. 1. Результаты исследования ответов респондентов по проблеме оправданности (целесообразности) удаленного формата работы на начало 2 квартала 2020 года

Так, например, процедура оценки качества образования [1, с. 65] стала практически сразу наиболее актуальным звеном в рамках высшей школы во всем современном мире. Не исключением здесь стала и Российская Федерация [3, 4], высшие образовательным учреждения которой остро столкнулись со снижением многих показателей эффективности своей деятельности. Многие проблемы также возникли здесь и при оценке качества самого процесса образования, который, ввиду сложившейся ситуации, стал менее открытым и прозрачным.

По данным многих независимых исследователей средний уровень проблемности оценки качества образования в высшей школе Российской Федерации во втором квартале 2020 года резко увеличился более чем в два раза (рис. 2).

Данные рисунка свидетельствуют о том, что в целом за 2019 год средний уровень анализируемого показателя оставался практически неизменным. Так с 1 квартала 2019 года по 4 квартал 2019 года, ввиду тех или иных причин, он уменьшился на 1,8 процента. Наибольшее значение среднего уровня проблемности оценки качества образования в высшей школе Российской Федерации здесь имело место во 2 квартале 2019 года и составило 24,5 процента. Меньше же всего средний уровень проблемности оценки качества образования в Российской Федерации в 2019 году имел место в 4 квартале и составил 22,1 процента. Усредненное значение анализируемого показателя за весь 2019 год составило 23,53 процента. В первом квартале 2020 года, относительно четвертого квартала 2019 года можно наблюдать рост в 2,6 процента. Указанное изменение, вероятнее всего, на наш взгляд, было вызвано переходящими годовыми контрольными точками и внедрением передовых образовательных стандартов последнего поколения.

Основной рост анализируемого показателя приходился именно на второй квартал 2020 года (начало глобальной пандемии). В целом за данный период изменение составило порядка 28,1 процента или в 2,14 раза. Значимых при- 


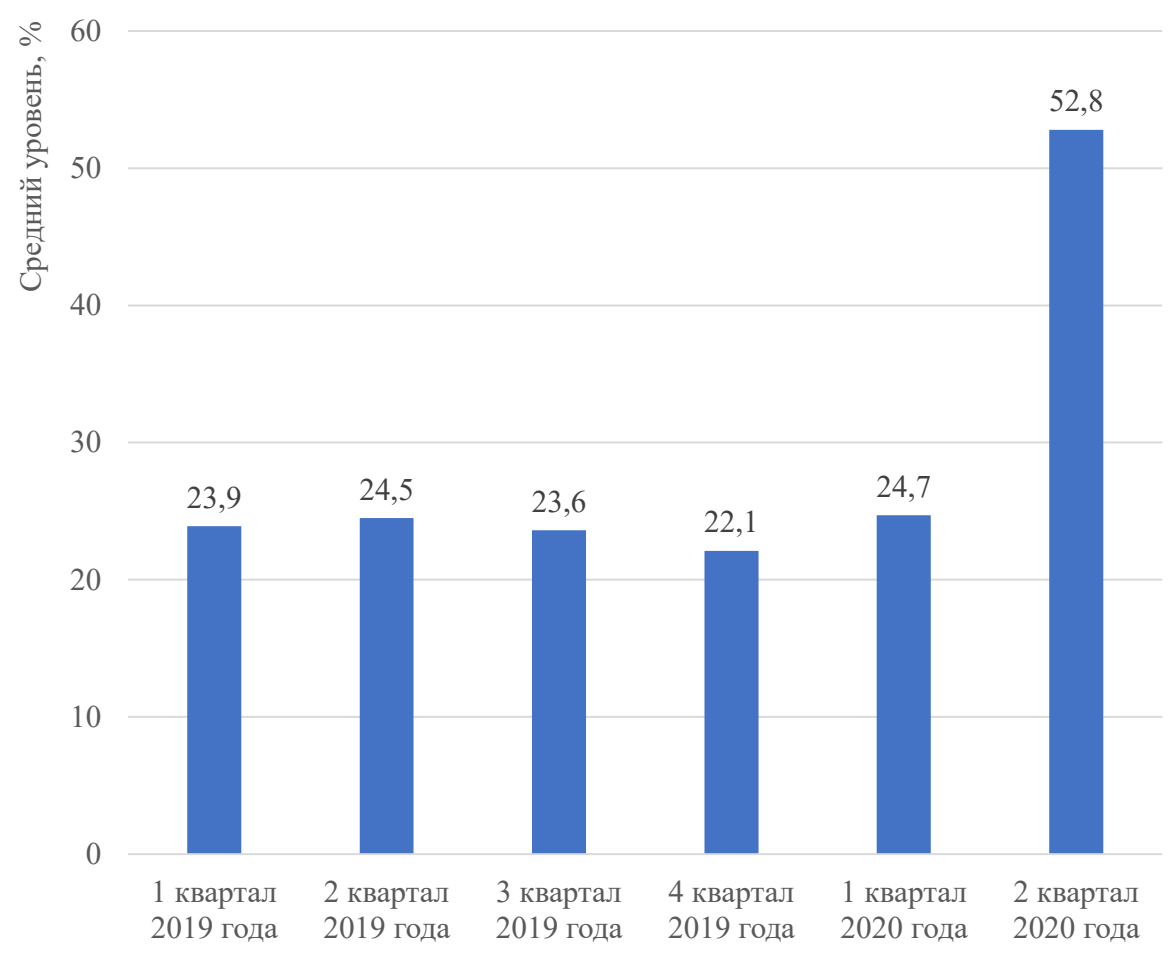

Puc. 2. Средний уровень проблемности оценки качества образования в высшей школе Российской Федерации в 2019-2020 годах с поквартальной разбивкой

чин произошедшего, на наш взгляд, достаточно много. Здесь можно выделить и сложности конвертации результатов работы субъектов (превалирующее влияние) в удаленном формате и отсутствие единых стандартов оценки в непредвиденных условиях и низкую релевантность передаваемой информации.

По прогнозам на третий квартал 2020 года значение усреднённого показателя проблемности оценки качества образования в высшей школе Российской Федерации будет приближено к отметке в 60 процентов. То есть негативная тенденция некоторым образом замедлится, но в целом сохранится на предельно высоком уровне.

Для нейтрализации (нивелирования) причин, вызвавших появление указанной тенденции, на наш взгляд, в Российской Федерации целесообразно реализовать следующий комплекс мер:

- разработать единую методологию оценки качества образования в высшей школе, учитывающую влияние обучения в дистанционном формате по всем актуальным направлениям. Данная мера может значительно увеличить процент точности измерения конечных данных (структурная и интегральная форма) и позволит формализовать процесс их дальнейшего распре- деления и перераспределения;

- назначить ответственных (группы ответственных) в каждом учебном заведении высшей школы за неукоснительное соблюдение всех групп разработанных требований (безотносительно влияния объективных факторов). Это, на наш взгляд, может ускорить процесс оценки анализируемого показателя (как в целом, так и его составных компонентов) и повысить качество достигнутых результатов в целом в текущей, среднесрочной и долгосрочной перспективах (последнее будет актуально, если действие глобальной пандемии в мировом масштабе сохранится больше одного календарного года);

- внедрить относительные индикаторы результативности для подразделений высших школ, учитывающих особенности их оперативной и стратегической деятельности. Указанное действие может способствовать закреплению достигнутых результатов в общих и специфических пространствах заведений, а также повысить уровень мотивации персонала на улучшение своих показателей в количественной (превалирующая ориентация) и качественной (второстепенная ориентация) проекциях.

Таким образом, можно сделать вывод, что в условиях мирового финансового кризиса и 
пандемии коронавирусной инфекции традиционные методики оценки качества образования в высшей школе уже не являются достаточно актуальными и требуют корректировки, исходя из влияющих на них факторов. Указанный тезис практически единогласно поддерживает большинство респондентов из таких развитых стран мира, как США, Италия, Китай, Германия, Франция и Россия.

С учетом глобального перехода высшей шко- лы на дистанционный формат обучения весьма оправданным становится механизм тотального контроля качества его осуществления.

Для разработки данного механизма в Российской Федерации, на наш взгляд, единая методология оценка качества анализируемого показателя, назначение комплекса ответственных сотрудников и внедрение относительных индикаторов результативности.

\section{Библиографический список}

1. Белоусов К.Ю. Измерительные процедуры и рейтингование в рамках общероссийской и региональной систем оценки качества образования / К. Ю. Белоусов // Проблемы современного образования - Москва: Издво: «Московский педагогический государственный университет», 2019. - № 2.- С. 61-71.

2. Пищугина И.А. Снижение уровня учебной мотивации обучающихся очной формы обучения в процессе дистанционного обучения в период самоизоляции / И.А.Пищугина // Вестник научных конференций Тамбов: Изд-во ООО «Консалтинговая компания Юком», 2020. - № 4-2.- С. 82-83.

3. Соловьева Т.В. Многоуровневая система оценки качества образования (МСОКО) как составляющая мониторинга качества образования в образовательной организации / Т. В. Соловьева // Управление качеством образования: теория и практика эффективного администрирования - Санкт-Петербург: Изд-во: «Эффектико Групп», 2019. - № 2.- С. 47-50.

4. Тамбовцев В.Л., Рождественская И. А. Менеджмент качества высшего образования: что означает «качество» и что означает «высшее образование»? / В.Л. Тамбовцев, И.А. Рождественская // Управленец - Екатеринбург.: Изд-во: «Уральский государственный экономический университет», 2020._№ 1.- С. 2-14.

5. Шатуновский В.Л., Шатуновская Е. А. Ещё раз о дистанционном обучении (организация и обеспечение дистанционного обучения) / В. Л. Шатуновский, Е.А. Шатуновская // Вестник науки и образования - Иваново: Изд-во: «Олимп», 2020.- № 9-1.- С. 53-56.

6. Компания «Эксперт РА» [Электронный ресурс]: аналитические материалы - Официальный сайт компании «Эксперт РА», 2020.- Режим доступа: www.raexpert.ru

7. Компания «PricewaterhouseCoopers» [Электронный ресурс]: аналитические материалы - Официальный сайт компании «PricewaterhouseCoopers», 2020.- Режим доступа: https://www.pwc.ru/ 